\title{
The Integration of Theory and Practice in the Education of Canadian Teacher
}

\author{
Ken Stevens \\ Faculty of Education, Memorial University of Newfoundland, Canada
}

\begin{abstract}
This three-year Canadian study in the professional education of teachers had two dimensions: the integration of theory with teaching practice and the integration of physical and virtual learning environments. It sought to answer two questions: (i) can teaching practice assist understanding of educational theory and (ii) can the digital school environment in which preservice teachers will be employed be used to enhance their professional education by linking practicing teachers with pre-service teachers in university courses? The first question was considered in relation to selected practicing teachers who volunteered to become Professional Associates of the university's Faculty of Education, in which role they engaged directly with pre-service teachers. The second question was considered within the concept of cybercells that enabled pre-service teachers in face-to-face university courses and virtual visitors from schools to engage in discussion and reflection about issues of mutual professional interest. The study found that pre-service teachers could improve their understanding of educational theory by engaging directly with practicing teachers with whom they discussed ideas and concepts. Preservice teachers further reported that their understanding of the digital environment was improved through engagement with practicing teachers in their university studies.
\end{abstract}

\section{Introduction}

The digital environment facilitates connections between classrooms and schools as well as between teachers and students, enabling collaborative virtual teaching and learning to take place. The development of collaborative virtual teaching and learning structures has the potential to expand learning opportunities and reduce educational inequalities, particularly for people who are educated beyond major centres of population. In the predominantly rural Canadian province of Newfoundland and Labrador these developments were extended to link practicing teachers in schools and pre-service teachers enrolled in a university Faculty of Education. In research that was undertaken to explore the possibility of strengthening educational theory in pre-service university courses by linking it with current teaching practices in the province's schools, university lecture rooms and school classrooms engaged with each other in the professional education of teachers.

The study took place in the Canadian province of Newfoundland and Labrador - the most eastern area of the country - whose population of approximately half a million people is concentrated in the island of Newfoundland, mostly in the capital city, St John's. Less than 30,000 people live in Labrador. A feature of the province is its rural nature and its many small schools located in dispersed coastal communities. Many students preparing for teaching positions in Newfoundland and Labrador expect to begin their careers in one of the many small rural schools in the province. A feature of education in Newfoundland and Labrador is the Centre for Distance Learning and Innovation (CDLI) which is part of the provincial government's Department (Ministry) of Education. CDLI provides access to internet-based courses to schools throughout Newfoundland and Labrador to supplement on-site teaching in mostly small schools throughout the province. Teachers in CDLI teach online to the province's dispersed schools and is a central feature of Newfoundland and Labrador's digital educational environment.

The preparation of teachers for schools in an increasingly digital and connected educational environment challenges traditional thinking about teaching, learning and access to knowledge, including professional knowledge $[2,6,7]$. In spite of the dispersed location of rural schools in the province, many of their classrooms have open, collaborative teaching and learning relations with one another, mediated by the provincial government's Centre for Distance Learning and Innovation. In this research project, the open and 
collaborative provincial educational structure was extended to include pre-service teachers undertaking Education courses in the university so that they could engage directly with self-selected practicing teachers throughout Newfoundland and Labrador in a learning community.

The notion of a learning community is an adaptation of the concept of the learning organization within which people continually seek ways to learn together [8]. Poole [5] noted that pre-service teacher development is an ideal time to introduce teacher candidates to the larger community of their profession and to the tools that can provide them with access to continued learning within an online community of practice. A salient benefit of communities of practice is the bridging of formal organizational boundaries in order to increase the collective knowledge, skills and professional trust and reciprocity of practitioners who serve in these organizations [10]. Herington [3] and Ingersol [4] both found evidence to indicate that beginning teachers who participated in an induction program with experienced teachers during their first year of teaching were less likely to leave the profession.

This study had two dimensions: the integration of theory with teaching practice and the integration of physical and virtual learning environments. It sought to answer two questions: (i) can teaching practice assist understanding of educational theory and (ii) can the digital school environment in which pre-service teachers will be employed be used to enhance their professional education by linking practicing teachers in schools with preservice teachers in university courses?

\section{The Integration of Educational Theory with Teaching Practice}

It is sometimes difficult for pre-service teachers enrolled in faculties of education to appreciate the role of theories, particularly those of a sociological nature, in their professional socialization. At Memorial University of Newfoundland a relationship between sociological theories of education and teaching practice has been organized based on practicing teachers who are recent graduates of the B.Ed. (IntermediateSecondary) program who have volunteered to become Professional Associates of the Faculty of Education. Professional Associates assist in the teaching of selected courses for pre-service teachers from their schools. The professional associate program enables classroom teachers to participate in lecture and seminar rooms at the university by sharing their practical skills and recent academic studies to enrich the preparation of pre-service teachers for classroom work in the near future.

The one-year professional educational program for graduates preparing to become intermediate and secondary teachers consists of three semesters covering a full year. The program begins in September and the first (fall) semester ends in December, after which the winter semester (January to April) is spent as full-time interns in schools. The third and final semester between May and August involves further coursework at the university. The professional program consists of both coursework based on educational theory and a full semester of teaching practice in selected schools.

Pre-service teachers in the fall semester section of the professional program are introduced to a range of educational and sociological theories relating to schools and socialization, critical social theory, knowledge and the curriculum, conflict and consensus theories of school and classroom organization as well as the organization of teaching and learning. After their return to campus following the internship, these theories are revisited and examined in the light of recent classroom experiences. Pre-service teachers are asked to examine theories they were introduced to in the fall in relation to their teaching and classroom work during the winter semester. In considering the relationship between theory and practice, pre-service teachers are encouraged to engage with practicing teachers who are Professional Associates of the Faculty of Education.

\section{The Integration of Physical and Virtual Learning Environments}

In the final semester of the B.Ed. (Intermediate-Secondary) program, following the winter internship, students complete additional academic courses including one that focuses on sociological considerations of classrooms and schools. Learning circles are used to discuss intern experiences in schools and the sociological implications of their classroom teaching, classroom culture and school culture. Learning circles are heterogeneous in composition in that they each consist of around eight students, as far as possible from different subject backgrounds. 
For example, history interns (teachers) sit with mathematicians, art educators, physical education specialists and others to find common sociological dimensions in their recent experiences in schools [1]. This involves reflection, discussion and academic reading as well as whole class presentations of their interpretations. In learning circles, collaboration is emphasized and students are encouraged to share their ideas and their readings on a range of sociological theories ranging from consensus and conflict, critical pedagogy and social and cultural reproduction and relate them to their recent internship experiences. Members of learning circles are in this way expected to link their recent classroom experiences with academic reading and, if possible, relate both to an appropriate sociological perspective. To facilitate this the concept of cybercells was introduced. A cybercell is a threshold concept in the professional work of teachers that describes the integration of actual and virtual groups in which face to face members extend their discussions to collaborate with virtual visitors [9]. Cybercells enable groups of people meeting in physical spaces to engage with virtual visitors using a range of contemporary and emerging technologies. By joining a cybercell from a distance, physicallyisolated people such as those in rural communities, can become part of actual groups in real time, able to be seen and heard and, thereby, contribute to discussions. There are spatial, cultural, social and technological dimensions of cybercells to be considered. Spatially, cybercells make physical spaces larger by including within them, virtual visitors on demand. Cybercells challenge institutions by extending their physical space to include virtual members such as other students, specialists and experts. The location of teachers and learners in relation to one another reduces in significance as virtual and actual teaching and learning spaces interact and merge in pursuit of common interests. Culturally, cybercells can change classrooms and other physical spaces by facilitating new understandings between groups that are both actually and virtually present. The culture of a classroom has the potential to be changed through reality-sharing in a cybercell between those who have an actual presence and those who enter a physical space virtually. Socially, collaborative teaching and collaborative learning are facilitated by the linking of physical and virtual spaces. One possible outcome of the advent of cybercells in teaching and learning is transformation of the concept of education as something that happens only in schools and in school time. Cybercells increasingly make use of new technologies, including interaction facilitated by Web 2.0, to reconstitute learning environments that extend beyond the physical confines of classrooms.

In this study the face-to-face groups were learning circles in a post-internship course at Memorial University of Newfoundland and the virtual visitors were Professional Associates in schools, all former members of the same intermediate-secondary education course. Learning circles are intended to promote collaboration between teachers (in actual and, in this case, virtual ways) and the development of shared realities that promote discussion and understanding of classrooms, schools and teaching.

\section{Professional Associates \& the Development of Portfolios}

Before the internship pre-service intermediate / secondary teachers $(\mathrm{N}=160)$ undertook a compulsory course, "Teaching and the Contemporary Classroom" and after the internship in schools were required to take a further course, "Perspectives on Schooling." In 2007, the first year of teaching this course using Teaching Associates (PAs) in schools, the Professor was assisted by 27 PAs. The following year the number of PAs increased to 66 and in 2010 there were 49. Professional Associates were all graduates of the Memorial University teacher education program and were aware of its theoretical as well as practical content. Before the academic year began the professor consulted Professional Associates in the design of the course and each participant was provided with course details. By recruiting PAs each year there was a measure of continuity between current and former members of the above courses. Professional Associates were invited to comment on and contribute to the design of the course that was taught through learning circles in which teaching, classroom culture and school culture were examined, linking recent intern experiences with academic reading. In Newfoundland and Labrador the Professional Associate program has meant that teachers in the province's schools participated in the preparation of pre-service teachers for classrooms. Pre-service teachers were asked to prepare portfolios of their internship experiences and to link these to their reading in the sociology of education. The development of portfolios began with an awareness of the increasingly open nature of teaching and learning in the province's 
schools in which teachers and students were increasingly able to collaborate with one another across multiple sites. Collaboration was encouraged at the post-intern phase of teacher education through learning circles in which professional associates from schools were in many cases engaged for discussion, feedback and critical comment. Pre-service teachers were encouraged to collaborate in two ways - with their peers in class through sharing experiences and perspectives in learning circles and with professional associates, as appropriate. Through face-to-face learning circles in class and through collaboration with practicing teachers in cybercells who joined the class as Professional Associates, teaching and learning realities were developed and shared. Collaboration between pre-service and practicing teachers included discussion about rural-urban differences in the provision of education, ways in which teachers can contribute to student career choices, how e-learning can enhance educational opportunities and even discussion of sociological theories and their application in day to day classroom life.

In the first year of the program (2007) preservice teachers were asked in a questionnaire about the value of Professional Associates in their professional education, including understanding the role of educational and sociological theory. The responses were that Professional Associates had:

- $\quad$ High Value $(\mathrm{N}=5,14 \%)$

- $\quad$ Moderate Value $(\mathrm{N}=18,51.5 \%)$

- $\quad$ Neutral $(\mathrm{N}=7,20 \%)$

- $\quad$ Low Value $(\mathrm{N}=3,8.5 \%)$

- $\quad$ No Value $(\mathrm{N}=2,6 \%)$

Two years later, in the third year of the program (2009) pre-service teachers were asked the same question in a further questionnaire. Their responses were that Professional Associates had:

- $\quad$ High Value $(\mathrm{N}=33) 62 \%$

- $\quad$ Moderate Value (N=19) $36 \%$

- $\quad$ Neutral $(\mathrm{N}=1) 2 \%$

- Low Value $(\mathrm{N}=0)$

- $\quad$ No Value $(\mathrm{N}=0)$

Pre-service teachers saw a number of advantages for themselves in online relationships, through cybercells, with practicing teachers who volunteered to be Professional Associates of the Faculty of Education. One pre-service teacher perceived value in the "fusion of academic \& practical" aspects of the professional education program. Another said she "welcomed the opportunity to learn from another teacher's style \& experience" and a third pre-service teacher thought there was value for him having a direct professional link between the university directly to schools so that he could "be involved with current issues and trends in education." Another preservice teacher saw the value of Professional Associates in "exposure to new ideas if my knowledge is limited" and another said simply that it enabled pre-service and practicing teachers to "learn from one another and to create together." The above comments are summarized in the words of the pre-service teacher who thought that "teacher collaboration is important for professional development."

\section{Social and Scholarly Significance of the Study}

The study took place in a province whose schools have been technologically enhanced over the last decade so that, largely through CDLI, teachers, students and classes can engage with one another across dispersed sites. This study built upon the developed interconnections between the province's schools by linking university classes to them. The scholarly significance of this study was in the fusion of actual (face-to-face) and virtual teaching using cybercells in providing university students preparing to become teachers with direct access to classroom teachers' knowledge to support and extend their academic reading and discussions. The social relevance of the study was in the linking of educational theory in intermediate - secondary courses at a university with real-life classrooms in Newfoundland and Labrador schools. Links between pre-service and in-service teachers were enhanced through discussion of shared issues and the realization that professional knowledge could be built collaboratively.

\section{Conclusion}

This study sought to answer two questions: (i) can teaching practice assist understanding of educational theory and (ii) can the digital school environment in which pre-service teachers will be employed enhance their professional education by linking practicing teachers in schools with preservice teachers in university courses?

By the end of the third year of the study most pre-service teachers accepted the fusion of academic and practical knowledge and the links 
between lecture rooms and classrooms. Collaboration between pre-service and in-service teachers enabled educational experiences to be shared and facilitated knowledge-building between schools and the university. The above pre-service teacher responses suggest that teaching practice does assist understanding of educational theory in intermediate - secondary courses at Memorial University of Newfoundland through face-to-face examination of issues common across subject areas in learning circles and, where appropriate, by engaging selected Professional Associates from schools.

Collaboration between pre-service and practicing teachers in the digital school environment of Newfoundland and Labrador enabled real-life classroom experiences to be shared in a community of practice, providing the former with a sense of the immediacy of classroom life that awaited them at the conclusion of their one-year graduate program.

\section{References}

[1] Coady, A., Churchill, R. \& Stevens K., (2012). "From Classrooms to Lecture Rooms Professional Associates and the Professional Education of Teachers," Bulletin of the Newfoundland and Labrador Teachers' Association 55 (6), 2012, pp. 20-21.

[2] Ertl, H. and Plante, J., Connectivity and Learning in Canada's Schools, Statistics Canada, Government of Canada, Ottawa, 2006.

[3] Herrington, A., Herrington, J., Kervin, L., \& Ferry, B., "The Design of an Online Community of Practice for Beginning Teachers," Contemporary Issues in Technology and Teacher Education, 6 (1) (2006) pp.120-132.

[4] Ingersoll, R., \& Kralik, J. M., The Impact of Mentoring on Teacher Retention: What the Research Says. Education Commission of the States, Denver, 2004.

[5] Poole, M. J., Developing Online Communities of Practice in Pre-service Teacher Education. 2000. Retrieved September 27, 2006 from http://citeseer.ist.psu.edu/update/508413.

[6] Schrum, L., "E-Learning and K-12", in Howard, C., Boettcher, J.V., Justice, L., Schenk, K., Rogers, P.L and Berg, G.A. (eds) Encyclopedia of Distance Learning, Idea Group Reference, Hershey, 2005, pp. 737-742.
[7] Stevens, K.J., "E-Learning and the Development of Open Classes for Rural Students in Atlantic Canada", In: The Open Classroom Distance Learning In and Out of Schools, Jo Bradley (ed), Kogan Page, London \& Sterling, VA. 2003, pp.149-157.

[8] Stevens, K.J., “Online Learning Communities for Canadian Teachers", Distance Education Quarterly, 11 (7) Autumn, 2011. Pp. 6-7.

[9] Stevens, K. \& Stewart, D., Cybercells Learning in Actual and Virtual Groups, ThomsonDunmore Press, Melbourne, 2005.

[10] Thompson, J., Bakken, L. \& Clark, F. L., "Creating Synergy: Collaborative Research Within a Professional Development School Partnership", The Teacher Educator, 37 (1), 2001, pp. 49 - 57.

\section{Acknowledgement}

This study was supported by the Social Sciences and Humanities Research Council (SSHRC) of Canada through a CommunityUniversity Research Alliance (CURA) award. 